\title{
Novel Therapy of the Carcinoid Syndrome Related Diarrhea
} \author{
Rașcu $^{6}$ and Viorel Scripcariu ${ }^{7}$ \\ ${ }^{1}$ Assistant Professor, Carol Davila University of Medicine and Pharmacy, Bucharest, Romania \\ ${ }^{2}$ Associate Professor, Grigore T Popa University of Medicine and Pharmacy, Romania \\ ${ }^{3}$ Associate Professor, Ovidius University of Constanța, Romania \\ ${ }^{4}$ Assistant Professor, Medicine Faculty, Ovidius University of Constanța, Romania \\ ${ }^{5}$ Medical Student, Medicine Faculty, Ovidius University of Constanța, Romania \\ ${ }^{6}$ Professor, Carol Davila University of Medicine and Pharmacy Bucharest, Romania \\ ${ }^{7}$ Professor, Grigore T Popa University of Medicine and Pharmacy Iasi, Romania
}

Marina Ruxandra Oțelea ${ }^{1 *}$, Sabina Antoniu ${ }^{2}$, Emma Gheorghe $^{3 *}$, Mădălina Iliescu ${ }^{4}$, Ioan Anton Arghir ${ }^{5}$, Agripina

Received: 紫 July 24, 2018; Published: 䠊 August 01, 2018

*Corresponding author: Marina Ruxandra Oțelea, Carol Davila University of Medicine and Pharmacy, Bucharest, Romania,

Emma Gheorghe, Associate Professor, Ovidius University of Constanța, Romania

\begin{abstract}
Carcinoid syndrome, characterized by symptoms such as diarrhea, flushing or wheezing, is caused by an excessive production of serotonin. Diarrhea and excessive bowel movement negatively affects the quality of life of these patients. Somatostatin analogues are efficacious but cannot optimally control symptoms. A review of clinical efficacy data in supporting the therapeutic indication for orphan drug designation is presented focused on the new approved drug, telotristat ethyl, an inhibitor of the tryptophan hydroxylase type I enzyme involved in the synthesis of serotonin. By depleting serotonin in the gastrointestinal tract, telotristat ethyl interrupts the pathological chain process of the diarrhea and demonstrated efficacy in patients with carcinoid syndrome.
\end{abstract}

Keywords: Diarrhea; Telotristat Ethyl; Carcinoid Syndrome

Abbreviations: TPH: Tryptophan Hydroxylase; SERT: Serotonin-Selective Reuptake Transporter; FDA: Food and Drug Administration; DLT: Dose Limiting Toxicity; SA: Somatostatin Analogues

\section{Introduction}

Carcinoid tumors are a subset of functional neuroendocrine tumors which can develop in lungs, thymus, small intestine, ovary, thyroid glands [1]. The carcinoid syndrome, caused by an excessive production of serotonin, occurs in less than $10 \%$ of the neuroendocrine tumors and manifest with typical symptoms of diarrhea, abdominal pain and flushing. These tumors can also secrete other hormones such as growth hormone, insulin, glucagon, vasoactive intestinal peptide or parathyroide hormone related peptide. The incidence is increasing, in part due to accessibility to diagnosis and on physician awareness about these forms of tumors [1], but also to environmental factors, such as smoking or asbestos exposure [2-4] that have been recently linked to the development of the neuroendocrine tumors. The diagnosis is based on symptoms, biological markers (hormones, serotonin or metabolites), imaging identification and histologic confirmation. The WHO classification requires histology, mitotic count and proliferation index determined by the percent of cells staining positively with a monoclonal antibody directed against a nuclear antigen in the proliferating cells (KI-67/MIB-1) [5].

The evolution is slow and pauci-or even asymptomatic; most cases are diagnosed during the metastatic stage [6]. Surgical approach has curative potential, with limited efficacy in advanced (symptomatic) carcinoids [7]. Conservative therapies, currently, used in carcinoid tumors, are represented by somatostatin analogues, interferon, systemic chemotherapy, and tyrosin kinase inhibitors.

\section{Aim}

To review the current knowledge of the pathophysiology of diarrhea in the carcinoid syndrome and of the therapeutic solution provided by tryptophan hydroxylase inhibitors for the symptomatic treatment of the carcinoid syndrome. 


\section{Pathophysiology of Diarrhea in the Carcinoid Syndrome}

Diarrhea occurs in $80 \%$ of carcinoid patients explosive, non loody, watery, with or without abdominal cramping and flushing [8] that negatively affects several dimensions of the patients' quality of life. Beside emotional and physical inconveniences, social and even occupational well-being is interfering. The gut could be considered a diffuse endocrine system, with 14 endocrine cells currently characterized producing at least 33 hormones and biogenic amines [9]. The histologic and functional similarities of these cells with the neural ones make them produce bioactive substances with endocrine, autocrine or paracrine transmitter function. Chromogranin-A is the best nonspecific marker of neuroendocrine tumors [10], but for the carcinoid syndrome diagnostic an elevated blood level of serotonin (5-HT) or of 5-hydroxiindolacetic acid (the serotonin metabolite) in a 24-hour urine are required.

The high level of 5HT in carcinoid syndrome plays a key role in the pathophysiology of diarrhea. Serotonin is synthetized from tryptophan in the neuroendocrine gut cells following chemical and mechanical induced stimulation. Tryptophan hydroxylase (TPH) catalyzes the initial and rate-limiting step in serotonin biosynthesis, the hydroxylation of L-tryptophan to 5-hydroxytryptophan. Human cells express 2 isoforms of tryptophan hydrolase, THP1 and TPH2, encoded by genes located on different chromosomes. THP1 is expresses in many tissues, including the gut, while TPH2 is neuro specific [11]. Apart from the increase in colonic lumen pressure and in the lumenal content THP1 expression regulators, the level of colon and blood 5HT is significantly influenced by the microbiota. In health, the spore forming bacteria promote colonic 5HT biosynthesis in neuroendocrine cells by direct metabolic signals on TPH1 expression [12]. The microbiota is able to modify the luminal content of the short chain fatty acid; in mice colonized with human gut microbiota, the short fatty acid content influenced TPH1 expression in a concentration-dependent manner [13].

Serotonin can be degraded only by intracellular enzymes and needs an active serotonin-selective reuptake transporter (SERT) in epithelial cells removing the 5-HT from the extracellular space. The 5-HT that escapes degradation enters the circulation via the capillary of the lamina propria and is taken up by platelets. If platelet have a dysfunctional SERT [14] or if their capacity is overpassed, $5 \mathrm{HT}$ is detected in the portal circulation, reaches the liver, where it is partially metabolized (and inactivated) by glucuronidation. The glucuronide-5-HT metabolite is hydroxylated by bacterial $\beta$-glucuronidase, gaining its biological activity and conferring an additional role of 5HT enhancement to the microbiota [15].

Conventional and non-conventional actions of 5-HT in the gut have been described [16]. Among the first, motility, secretion and vasodilatation are the best characterized. However, recent research gave new perspectives on these mechanisms. For example, in normal individuals, the 5-HT release is no more considered the initiator of the peristaltic reflex [17], still having and important role in the segmentation process and in the integration of the stretch reflexes with the propulsive motility [18]. Serotonin initiates the secretion process that contributes to the dilution and neutralization of the luminal content. The mechanism involves the stimulation of the afferent neurons from the myenteric plexus; through interneuron connections, acetylcholine is released and secretoneurons from the submucosal plexus are activated; the axons of these neurons reach both the vilous and the crypts regions, stimulate water, sodium, chloride and bicarbonate secretion in crypts and inhibit the nutrient independent salt absorption in villi [19]. Serotonin also increases the intracellular calcium content in the epithelial intestinal cell, inhibiting sodium absorption, in a proteinkinaze C-dependent manner. Activation of proteinkinaze $\mathrm{C}$ inhibits the intestinal sodium/hydrogen exchanger 3 (NHE3) by stimulating the endocytosis of NHE3 from the brush border; reducing the membrane number of molecules of NHE3 significantly diminishes the neutral sodium absorption [20]. The third conventional action of serotonin is vasodilatation. Aside the systemic effect, clinically expressed by flushing, 5-HT exerts influence on local gut circuits by activation of the submucosal and myenteric plexus reflexes [21]. All conventional actions participate to the pathogenesis of the diarrhea.

The non-conventional effects of 5HT emerged from various experimental data. In deficient mice models, 5 -HT had a regulatory role in the development and the survival of enteric neurons [22] and in preserving the integrity of the interstitial cells of Cajal [23]. All together, these $5 \mathrm{HT}$ biological actions contribute to the coordinated reflexes that regulate the intestinal transit.

The balance between the pro-inflammatory and the antiinflammatory effects of 5HT is an open field of investigation. In inflammation sites, extracellular 5-HT reduces cAMP in lymphocyte $\mathrm{T}$ cells, modeling the activation process and acts as a transmission signal in the immune synapse mechanism, by which communication is established between the antigen presenting and the lymphocyte cells. Dendritic cells express 5HT7 receptor [24] and SERT. They regulate T-cells differentiation by several processes, one of which is the serotonin uptake and shuttle from activated T-cells to the naive one [25]. Another important target for $5 \mathrm{HT}$ in dendritic cells is the Nf-kB pathway, with consequent impact on T-cell activation [26]. Immune cells have positive feedback on $5 \mathrm{HT}$ secretion, maintaining the pro-inflammatory status [27]. Even if there are more arguments for the pro-inflammatory effect, an anti-inflammatory activity of $5 \mathrm{HT}$ was also proposed. For example, in experimentally induced colitis, the activation of 5HT4 receptors enhances the intestinal epithelial cell proliferation and resistance to oxidative stress [28]. Findings related to irritative and inflammatory bowel diseases cannot be extrapolated to neuroendocrine tumors, even if the association of these clinical entities with carcinoid syndrome is more frequent than expected from data in general population [29]. As non-conventional 5HT effects might indirectly affect bowel movements and diarrhea by interfering the balance of the immune system of the gut, the effects of high levels of 5HT on the immunologic function of patients with carcinoid syndrome needs an in depth, specific evaluation.

Another rare, but possible mechanism of diarrhea in carcinoid syndrome is the interference of the bile acid flow. Carcinoid tumors are rarely located in the biliary tree [30]; progressively, they obstruct the biliar flow and lead to lipid malabsorption and steatorrhea. Another possible factor is the distal ileon resection 
of more than $100 \mathrm{~cm}$ during the surgical treatment of intestinal carcinoids. The large reduction of the reabsorption area interrupts the entero-hepatic circuit of the biliary acids and make them reach the colon, where they are able to stimulate salt and water secretion [31], determining the cholegenic diarrhea. Carcinoid tumors also secrete bradykinin, substance $\mathrm{P}$, and prostaglandins, all of which are secretory stimuli in the intestine. Liver metastasis, frequently present at diagnosis, reduce the hepatic clearance of these substances, contributing to the symptoms severity.

\section{Tryptophan Hydroxylase Inhibitors as Novel Therapy of Carcinoid Related Diarrhea}

Conservative therapies currently used in carcinoid tumors are represented by somatostatin analogues, interferon, systemic chemotherapy, and tyrosin kinase inhibitors with an unpredictable and rather modest efficacy on diarrhea, except for somatostatin analogues. The latter class, despite being regarded as the therapeutic mainstay in symptomatic carcinoid tumors can be associated with tachyphylaxis and with the risk of side-effects due to the use of overdoses needed to achieve symptomatic control [32]. Systemic chemotherapy is represented by 5-flourouracil, cisplatin, and streptozocin, either administered alone or in combination yields rather modest rates of therapeutic responses ranging from $5 \%$ with monotherapy to $30 \%$ with combinations [33]. Interferon-alpha was investigated in combination with chemotherapy in patients with intestinal carcinoids, yet its efficacy as a stand-alone therapy is not known Several investigational therapies are currently in late stages of clinical development for the treatment of carcinoid syndromes, most of them being antiangiogenic agents that act as tyrosin kinase inhibitors for various growth factors such as VEGF: bevacizumab, ziv-aflibercept or regorafenib have been so far studied for their antitumor activities in carcinoid tumors [34,35].

Another therapeutic class is represented by tryptophan hydroxylase inhibitors. Such compounds are currently under development for irritable bowel syndrome and for intestinal carcinoids and include telotristat etiprate (LX1032, LX1606, (S)ethyl 2-amino-3-(4-(2-amino-6((R)-1-(4-chloro-2-(3-methyl1H-pyrazol-1- yl) phenyl)-2,2,2-trifluoroethoxy) pyrimidin-4-yl) phenyl) propanoate), which is currently known as telotristat ethyl [36]. This novel therapy was evaluated in different clinical studies, granted and recommended by U.S.A. Food and Drug administration (FDA) and European Medicines Agency, and recently approved by these authorities for carcinoid related diarrhea syndrome [37-38].

The initial evidence that mice lacking TPH1 had very low blood serotonin levels, no serotonin synthesis in enterochromaffin cells into the guts, and preserved serotonin-dependent pathways in the nervous system prompted the discovery of TPH1 inhibitors, a Th1 inhibitor called LP-533401 (pro-drug for LX 1032) exhibited a potent inhibitory effect in vitro, and in vivo, on rat's models [10], due to its intracellular activation, via hydrolization, the IC50 being $0.7 \mu \mathrm{M}$ [39-41]. Telotristat ethyl binds to the TPH1 and competing with tryptophan. The direct effect is to block the rate limiting step of the 5HT synthesis [40]. Pharmacokinetics analysis for LX1031, parent compound of LX1032, in healthy volunteers, reported a half time of elimination about 20hours irrespective of the dose, with a Cmax of $84.4-384 \mathrm{ng} / \mathrm{mL}$, and multiphasic plasmatic elimination [42] In humans, 5HT levels decrease after 4-5 days after the initiation of the treatment and reach up to $20-40 \%$ of the initial level after 2 weeks of $1500 \mathrm{mg} /$ daily dose [43].

\section{Clinical Efficacy Studies of Telotristat Ethyl}

Table 1: Clinical efficacy data from phase II and III studies with telotristat ethyl in treatment of carcinoid syndrome.

\begin{tabular}{|c|c|c|c|c|c|}
\hline $\begin{array}{l}\text { Study clinical phase } \\
\text { and design }\end{array}$ & $\begin{array}{l}\text { Study population } \\
\text { and sample }\end{array}$ & Dosage & $\begin{array}{l}\text { Primary efficacy } \\
\text { endpoint }\end{array}$ & $\begin{array}{l}\text { Secondary efficacy } \\
\text { endpoints }\end{array}$ & Safety \\
\hline $\begin{array}{l}\text { Phase II, } \\
\text { randomized placebo- } \\
\text { controlled, dose- } \\
\text { escalating [14] }\end{array}$ & $\begin{array}{l}\text { Metastatic } \\
\text { carcinoid } \\
\text { syndrome, } n=23\end{array}$ & $\begin{array}{l}150 \mathrm{mg}, \\
250 \mathrm{mg}, \\
350 \mathrm{mg} \text { and } \\
500 \mathrm{mg} \text { tid }\end{array}$ & $\begin{array}{l}\text { Daily frequency, the } \\
\text { change in urinary 5- } \\
\text { hydroxyindoleacetic } \\
\text { acid (u5-HIAA), } \\
\text { symptoms severity, } \\
\text { flushing frequency, the } \\
\text { use of as needed short- } \\
\text { acting "rescue" } \\
\text { octreotide }\end{array}$ & $\begin{array}{l}\text { stool consistency, } \\
\text { urgency to defecate, } \\
\text { frequency of flushing } \\
\text { episodes and by } \\
\text { patient-reported } \\
\text { adequate relief }\end{array}$ & $\begin{array}{l}\text { Well tolerated } \\
\text { Incidence of adverse } \\
\text { events: } 100 \% \text { with } \\
\text { telotristat and } 80 \% \text { with } \\
\text { placebo, diarrhea the most } \\
\text { common }\end{array}$ \\
\hline $\begin{array}{l}\text { Phase II open label } \\
\text { dose escalating [15] }\end{array}$ & $\begin{array}{l}\text { Metastatic } \\
\text { carcinoid, } n=15\end{array}$ & $\begin{array}{l}150 \mathrm{mg}, \\
250 \mathrm{mg} \text {, } \\
350 \mathrm{mg} \text { and } \\
500 \mathrm{mg} \text { tid }\end{array}$ & \multicolumn{2}{|c|}{$\begin{array}{l}\text { Stools frequency, consistency, urinary 5-HIAA } \\
\text { levels, abdominal pain, flushing }\end{array}$} & $\begin{array}{l}\text { Gastrointestinal effects } \\
\text { most commonly reported }\end{array}$ \\
\hline $\begin{array}{l}\text { Phase III } \\
\text { TELESTAR [16] }\end{array}$ & $\begin{array}{l}\text { Metastatic } \\
\text { carcinoid } n=135\end{array}$ & $\begin{array}{l}250 \mathrm{mg}, \\
500 \mathrm{mg} \text { tid }\end{array}$ & Daily stool frequency & $\begin{array}{l}\text { uS-HIAA, number of } \\
\text { flushing episodes, } \\
\text { abdominal pain } \\
\text { EORTC-QLQ-C30 } \\
\text { scores, rescue short- } \\
\text { acting SAs use }\end{array}$ & $\begin{array}{l}\text { Comparable incidences of } \\
\text { adverse events, nausea the } \\
\text { most common adverse } \\
\text { event }\end{array}$ \\
\hline $\begin{array}{l}\text { Phase III } \\
\text { TELECAST [14] }\end{array}$ & $\begin{array}{l}\text { Metastatic } \\
\text { carcinoid } n=76\end{array}$ & $\begin{array}{l}250 \mathrm{mg} \\
500 \mathrm{mg} \text { tid }\end{array}$ & $\begin{array}{l}\text { Biochemical response } \\
\text { rate (reduction of } \\
\text { baseline u5-HIAA at } \\
\text { week } 12 \text { compared to } \\
\text { placebo) }\end{array}$ & Daily stool frequency & $\begin{array}{l}\text { Gastrointestinal adverse } \\
\text { events, } 57.7 \% \text { placebo, } \\
64 \% \text { telotristat lower dose, } \\
36 \% \text { telotristat higher dose }\end{array}$ \\
\hline
\end{tabular}

Legend: tid= three times a day 
An overview of the clinical studies [44-47] evaluating the efficacy of telotristat in carcinoid syndrome is provided in Table 1. The first 4 weeks randomized placebo controlled phase II study evaluating the clinical efficacy assessed in the first doseascending phase, four cohorts of 4 patients, 1 receiving placebo and 3 receiving ascending doses of $150 \mathrm{mg}, 250 \mathrm{mg}, 350 \mathrm{mg}$ and $500 \mathrm{mg}$ three times a day (tid) telotristat ethyl were enrolled [44]. In the expansion phase of the study, other 7 patients (6 receiving the active drug and one placebo) were evaluated, at maximum tolerated or at maximal study dose. Inclusion criteria consisted in the presence of biopsy-proven neuroendocrine tumor, in metastatic stage, and disease-related diarrhea, uncontrolled by octreotide. The exclusion criteria included poor performance status, diarrhea due to other causes, concomitant therapy with other compounds which could influence intestinal motility. $28 \%$ clinical responders were in pooled telotristat group, with complete response, at the 4th week compared to 0 in placebo arm, with adequate relief reported by $46 \%$ patients treated with teloristat and none in placebo group $(p=0.019)$. A reduction in stools frequency for $\geq 2$ weeks was reported in $12(75 \%)$ patients of telotristat group versus $1(20 \%)$ patient receiving placebo. Telotristat exerted no significant effect on rescue octreotide use, stool consistency, urgency to defecate, abdominal pain, flushing frequency as compared to placebo [44]. The second open-label phase II, dose-escalating, study performed in Germany and United Kingdom included 15 patients with carcinoid syndrome and neuroendocrine tumors in metastatic stage, in the presence of $\geq 4$ stools/day, irrespective of the existence of the therapy with somatostatin analogues in the current therapeutic regimen [45].

Severe patients (Karnofsky index $\leq 70$, hemodynamic instability due to blood volume loss, the presence of other causes of diarrhea, severe hepatic impairment) were excluded. Telotristat was given at $150 \mathrm{mg}$ tid for 2 weeks. If dose limiting toxicity (DLT) was not detected, the dose was progressively ascended, every two weeks, to $250 \mathrm{mg}$ tid, $350 \mathrm{mg}$, and, finally, $500 \mathrm{mg}$ tid for 2 weeks, with a total duration of dose- ascension of 8 weeks. The completion rate was $93 \%$ (14 patients), while the dose escalation up to $500 \mathrm{mg}$ tid was possible in 12 patients (80\%). DLT was defined by constipation manifested by absent stools for $>3$ consecutive days and with hepatic impairment (an increase in aminotransferases, in total bilirubin or in alkaline phosphatase). An extra 124 week study extension phase was available with 11 patients entering this phase, with 13 (87\%) receiving long-acting SSAs at the time of enrollment. The number of flushing episodes, abdominal pain and nausea severity scores were also reported to be reduced by week 12. The efficacy analysis consisted in decreased frequency of stools by $43.5 \%$, consistency score $(19.5 \%$ reduction, $\mathrm{p}<0.001)$, with no influence by the concomitant somatostatin analogues (SA) therapy, excepting one patient [45]. Two other phase III studies conducted with telotristat ethyl in carcinoid syndrome were TELESTAR [46] and TELECAST [47]. TELESTAR study enrolled adults aged at least 18 year-old, with neuroendocrine tumors of well-differentiated histological type in an advanced (metastatic) stage, with at least four stools daily and use of stable doses, during at least 3 months prior to study screening [46]. Exclusion criteria were severe diarrhea, associated with volume loss or enteric infection, poor performance status, short bowel syndrome, significant hepatic impairment, concomitant use of other antitumor therapy.

Two different dosages of telotristat ethyl $250 \mathrm{mg}$ respective $500 \mathrm{mg}$ tid) were compared with placebo over 12 weeks. The placebo-controlled period was followed by an open label phase for patients willing to take teloristat for 36 weeks. Per protocol sample included 41 patients in the telotristat lower dose arm, 38 patients in the telotristat higher dose arm and 38 patients in the placebo arm. Drug compliance to the scheduled doses was reported to be respectively $93.3 \%, 76 \%$ and $86.7 \%$. When this data was drafted, the open label extension phase enrolled 115 patients, 56 of them completing it. Compared to placebo, telotristat ethyl was able to decrease significantly the baseline daily stools frequency ( $\mathrm{p}<0.001$ ). Responders' rates were $44 \%, 42 \%$ and $20 \%$. The odds ratio to achieve a clinical response was 3.49 for telotristat lower dose and 3.11 for telotristat higher dose, versus placebo. The preliminary analysis reported a reduced stool frequency, with improved diarrhea score by 19.2 points in telotristat lower dose arm compared to placebo $(\mathrm{p}=0.039)$ and no significant therapeutic effect on flushing episodes, abdominal pain, nausea and vomiting subscale score [46]. TELECAST study had a similar design, included 76 patients, who were randomized to receive telotristat $250 \mathrm{mg}$ tid, $500 \mathrm{mg}$ tid and placebo for 12 weeks [47]. Patients experiencing at least one symptom or sign characteristic for carcinoid syndrome experienced at least every five days were eligible. The main efficacy endpoint was represented by the biochemical response of urine 5 hydroxyindoleacetic acid change from baseline to week 12 . Therapeutic effect was significant over placebo $(p<0.001)$, with a decreased daily stool frequency versus placebo $(p=0.004$ for telotristat lower dose and $\mathrm{p}<0.001$ for higher dose) [46].

\section{Safety and Tolerability of Telotristat Etyl}

Telotristat was found to be well tolerated over the whole drug escalation phase and during the extension phase, with transient elevation of hepatic enzymes (reported in both telotristat and placebo groups), severe nausea, recurrence of squamous cell carcinoma without any dose-response relationship in terms of incidence or severity of adverse events [44]. In the second phase study, performed in Europe, safety analysis reported mild adverse events (diarrhea, nausea, dysgeusia, inappetence), rare serious adverse events (hypertension, rhinitis and diarrhea respectively) and frequent gastrointestinal (66.7\%) and nervous system disorders (40\%) as the most common adverse events [45]. Safety analysis performed in TELESTAR study revealed comparable frequency of adverse events across study arms: nausea $31.1 \%$ with telotristat higher dosage, $13.3 \%$ with telotristat lower dosage and $11.1 \%$ with placebo), increased gamma-glutamyl transferase $(4 / 8.9 \%$ patients in each telotristat arm), depression or depression-like symptoms (6.7\% of patients in placebo and telotristat lower dosage versus $15.6 \%$ in telotristat higher dosage) [46]. In TELECAST study, the rate of serious adverse events was greater in placebo arm (19.2\%) versus telotristat lower and dose (4\% and $8 \%$ ), with a decreased rate of depressive symptoms in telotristat group (4\%) versus placebo (7.7\%) and increased gastrointestinal events $(57.7 \%$ in 
placebo arm, 64\% in telotristat lower dose arm and 36\% in higher dose arm [47].

The quality of life impact of telotristat ethyl was also assessed in the TELESTAR study; the treatment satisfaction directly correlated with the reduction in bowel movements frequency and was significantly higher in telotristat ethyl versus placebo patients [48]. Carcinoid syndrome has many future directions of research development, from exposure assessment [49] to new methodological approaches [50] or combined therapies to improve both symptoms and prognostic [51].

\section{Conclusion}

Inhibition of serotonin is an efficient therapeutic approach in carcinoid syndrome and telotristat ethyl is a promising novel therapy in carcinoid syndrome-related symptoms, reducing the severity of diarrhea and flushes in patients with advanced carcinoid tumors, with good tolerance and safety profile. The impact of telotristat on the survival rate is not yet known, and researchers will involve longer observational studies helpful for bronchial carcinoids in which diarrhea and asthma-like symptoms are the clinical hallmark of the disease.

\section{References}

1. Hendifar AE, Marchewsky AM, Tuli R (2017) Neuroendocrine Tumors of the Lung: Current Challenges and Advances in the Diagnosis and Management of Well-Differentiated Disease. J Thorac Oncol 12(3): 425436.

2. Clin B, Andujar P, Abd Al Samad I, Azpitarte C, Le Pimpec-Barthes F, et al. (2012) Pulmonary carcinoid tumors and asbestos exposure. Ann Occup Hyg 56(7): 789-795.

3. Goron M, Man M, Bondor C, Arghir O (2010) Risk Factors in the Etiology of Lung Cancer. WSEAS International Conference. Recent Advances in Clinical Medicine. ISI Proceedings University of Cambridge, UK, pp. 207212.

4. Arghir OC, Halichidis S, Cambrea SC, Ruta MV, Ciobotaru C, et al. (2014) Environmental Risk Factors for Lung Cancer in Never Smokers. J Environ Prot Ecol 15(1): 348-352.

5. Bosman F, Carneiro F, Hruban R (2010) WHO Classification of Tumors of the Digestive System. Lyon, France, IARC.

6. Pasricha G, Padhi P, Daboul N, Monga DK (2017) Management of Well-differentiated Gastroenteropancreatic Neuroendocrine Tumors (GEPNETs): A Review. Clin Ther 39(11): 2146-2157.

7. Bendelow J, Apps E, Jones LE, Poston GJ (2008) Carcinoid syndrome. Eur J Surgic Oncol 34(3): 289-296.

8. Creutzfeldt W (1996) Carcinoid tumors: Development of our knowledge. World J Surg 20(2):126-131.

9. Rindi G, Leiter AB, Kopin AS, Bordi C, Solcia E (2004) The "normal" endocrine cell of the gut: Changing concepts and new evidences. Ann N Y Acad Sci 1014(1): 1-12.

10. Warner RRP (2005) Enteroendocrine Tumors Other Than Carcinoid: A Review of Clinically Significant Advances. Gastroenterology 128(6): 1668-1684.

11. Carkaci-Salli N, Flanagan JM, Martz MK, Salli U, Walther DJ, et al. (2006) Functional Domains of Human Tryptophan Hydroxylase 2 (hTPH2). J Biol Chem 281(38): 28105-28112.

12. Yano JM, Yu K, Donaldson GP, Shastri GG, Ann P, et al. (2015) Indigenous Bacteria from the Gut Microbiota Regulate Host Serotonin Biosynthesis. Cell 161(2): 264-276.
13. Reigstad CS, Salmonson CE, Rainey JF, Szurszewski JH, Linden DR, et al. (2015) Gut microbes promote colonic serotonin production through an effect of short-chain fatty acids on enterochromaffin cells. FASEB J 29(4): 1395-1403.

14. Foley S, Garsed K, Singh G, Doroudier NP, Swan C, et al. (2011) Impaired uptake of serotonin by platelets from patients with irritable bowel syndrome correlates with duodenal immune activation. Gastroenterology 140(5): 1434-1443.

15. Hata T, Asano Y, Yoshihara K, Kimura-Todani T, Miyata N, et al. (2017) Regulation of gut luminal serotonin by commensal microbiota in mice. PLoS ONE 12(7): e0180745.

16. Mawe GM, Hoffman JM (2013) Serotonin Signaling in the Gastrointestinal Tract: Functions, dysfunctions, and therapeutic targets. Nat Rev Gastroenterol Hepatol 10(8): 473-486.

17. Li Z, Chalazonitis A, Huang YY, Mann JJ, Margolis KG, et al. (2011) Essential Roles of Enteric Neuronal Serotonin in Gastrointestinal Motility and the Development/Survival of Enteric Dopaminergic Neurons. J Neurosci. 31(24): 8998-9009.

18. Heredia DJ, Gershon MD, Koh SD, Corrigan RD, Okamoto T, et al. (2013) Important role of mucosal serotonin in colonic propulsion and peristaltic reflexes: In vitro analyses in mice lacking tryptophan hydroxylase 1. J Physiol 591(23): 5939-5957.

19. Surawicz CM (2010) Mechanims of diarrhea. Curr Gastroenterol Rep 12(4): 236-241.

20. Zachos NC, Kovbasnjuk O, Donowitz M (2009) Regulation of Intestinal Electroneutral Sodium Absorption and the Brush Border $\mathrm{Na}+\mathrm{H}+$ Exchanger (NHE3) by Intracellular Calcium. Ann N Y Acad Sci 1165(1): 240-248.

21. Vanner S (2000) Myenteric neurons activate submucosal vasodilator neurons in guinea pig ileum. Am J Physiol Gastrointest Liver Physiol 279(2): G380-G387.

22. Gross ER, Gershon MD, Margolis KG, Gertsberg ZV, Cowles RA (2012) Neuronal serotonin regulates growth of the intestinal mucosa in mice. Gastroenterology 143(2): 408-417.

23. Du P, O’Grady GO, Gibbons SJ, Yassi R, Lees-Green R, et al. (2010) Tissuespecific mathematical models of slow wave entrainment in wild-type and 5- HT(2B) knockout mice with altered interstitial cells of Cajal networks. Biophys J 98(9): 1772-1781.

24. Kim JJ, Bridle BW, Ghia JE, Wang H, Syed SN, et al. (2013) Targeted inhibition of serotonin type 7 (5-HT7) receptor function modulates immune responses and reduces the severity of intestinal inflammation. J Immunol 190(9): 4795-4804.

25. O'Connell PJ, Wang X, Leon-Ponte M, Griffiths C, Pingle SC, et al. (2006) A novel form of immune signaling revealed by transmission of the inflammatory mediator serotonin between dendritic cells and $\mathrm{T}$ cells. Blood 107(3): 1010-1017.

26. Li N, Ghia J-E, Wang H, McClemens J, Cote F, et al. (2011) Serotonin Activates Dendritic Cell Function in the Context of Gut Inflammation. Am J Pathol 178(2): 662-671.

27. Motomura Y, Ghia JE, Wang H, Akiho H, El-Sharkawy RT, et al. (2008) Enterochromaffin cell and 5- hydroxytryptamine responses to the same infectious agent differ in Th1 and Th2 dominant environments. Gut 57(4):475-481.

28. Spohn SN, Mawe GM (2017) Non-conventional features of peripheral serotonin signaling. Nat Rev Gastroenterol Hepatol 14(7): 412-420.

29. Sciola V, Massironi S, Conte D, Caprioli F, Ferrero S, et al. (2009) Plasma chromogranin a in patients with inflammatory bowel disease. Inflamm Bowel Dis 15(6): 867-871.

30. Nesi G, Lombardi A, Batignani G, Ficari F, Rubio CA, et al. (2006) Welldifferentiated endocrine tumor of the distal common bile duct: A case study and literature review. Virchows Arch 449(1): 104-111. 
31. Camilleri M (2015) Bile Acid Diarrhea: Prevalence, Pathogenesis, and Therapy. Gut Liver 9(3): 332-339.

32. Wolin EM (2012) The Expanding Role of Somatostatin Analogs in the Management of Neuroendocrine Tumors. Gastrointest Cancer Res 5(5): 161-168.

33. Gut P, Waligórska-Stachura J, Czarnywojtek A, Sawicka-Gutaj N, Bączyk M, et al. (2017) Management of the hormonal syndrome of neuroendocrine tumors. Arch Med Sci 13(3): 515-524.

34. Dahan L, Bonnetain F, Rougier P, Raoul JL, Gamelin E, et al. (2009) Phase III trial of chemotherapy using 5-fluorouracil and streptozotocin compared with interferon $\alpha$ for advanced carcinoid tumors: FNCLCCFFCD 9710. Endocr Relat Cancer 16(4):1351-1361.

35. Bendell JC, Zakari A, Lang E, Waterhouse D, Flora D, et al. (2016) A Phase II Study of the Combination of Bevacizumab, Pertuzumab, and Octreotide LAR for Patients with Advanced Neuroendocrine Cancers Cancer Investig 34(5): 213-219.

36. Camilleri M (2011) LX-1031, a Tryptophan 5-hydroxylase Inhibitor, and Its Potential in Chronic Diarrhea Associated with Increased Serotonin. Neurogastroenterol Motil 23(3): 193-200.

37. Markham A (2017) Telotristat Ethyl: First Approval. Drugs 77(7): 793798.

38. Agency EM (2017) Public summary of opinion on orphan designation: (S)-ethyl 2-amino-3-(4-(2 amino-6((R)-1-(4-chloro-2-(3-methyl-1Hpyrazol-1-yl)phenyl)-2,2,2-trifluoroethoxy) pyrimidin 4yl) phenyl) propanoate for the treatment of carcinoid tumours, p 1-5.

39. Shi ZC, Devasagayaraj A, Gu K, Jin H, Marinelli B, et al. (2008) Modulation of peripheral serotonin levels by novel tryptophan hydroxylase inhibitors for the potential treatment of functional gastrointestinal disorders. J Med Chem 51(13): 3684-3687

40. Cianchetta G, Stouch T, Yu W, Shi ZC, Tari LW, et al. (2010) Mechanism of Inhibition of Novel Tryptophan Hydroxylase Inhibitors Revealed by Cocrystal Structures and Kinetic Analysis. Curr Chem Genomics 4: 19-26.

41. Jin H, Cianchetta G, Devasagayaraj A, Gu K, Marinelli B, et al. (2009) Substituted 3-(4-(1,3,5-triazin-2-yl)- phenyl)-2-aminopropanoic acids

ISSN: 2574-1241

DOI: 10.26717/BJSTR.2018.07.001517

Marina Ruxandra Oțelea. Biomed J Sci \& Tech Res

(C) (P) This work is licensed under Creative

Submission Link: https://biomedres.us/submit-manuscript.php as novel tryptophan hydroxylase inhibitors. Bioorg Med Chem Lett 19(17): 5229-5232.

42. Brown PM, Jackson JI, Frazier KS, Turner CA, Shi ZC, et al. (2007) From Mouse Knockout to Investigational Drug LX1031, a Novel Potential Treatment for Irritable Bowel Syndrome. Am J Gastroenterol 102: S961.

43. Lapuerta P, Zambrowicz B, Fleming D, Wheeler D, Sands A (2015) Telotristat etiprate, a novel inhibitor of serotonin synthesis for the treatment of carcinoid syndrome. Clin Invest 5(5): 447-456.

44. Kulke MH, O’Dorisio T, Phan A, Bergsland E, Law L, et al. (2014) Telotristat etiprate, a novel serotonin synthesis inhibitor, in patients with carcinoid syndrome and diarrhea not adequately controlled by octreotide. Endocr Relat Cancer 21(5): 705-714.

45. Pavel M, Horsch D, Caplin M, Ramage J, Seufferlein T, et al. (2015) Telotristat etiprate for carcinoid syndrome: a single-arm, multicenter trial. J Clin Endocrinol Metab 100(4): 1511-1519.

46. Kulke MH, Horsch D, Caplin ME, Anthony LB, Bergsland E, et al. (2017) Telotristat Ethyl, a Tryptophan Hydroxylase Inhibitor for the Treatment of Carcinoid Syndrome. J Clin Oncol 35(1): 14-23.

47. Lexicon Pharma (2016) Telecast Data Presented at the 2016 North American Neuroendocrine Tumor Society Annual Symposium.

48. Anthony L, Ervin C, Lapuerta P, Kulke MH, Kunz P, et al. (2017) Understanding the Patient Experience with Carcinoid Syndrome: Exit Interviews from a Randomized, Placebo-controlled Study of Telotristat Ethyl. Clin Ther 39(11): 2158-2168.

49. Otelea M, Rascu A (2015) Genomics and proteomics techiques in nanoparticles studies-new approach in environmental research. Environ Engineer Manag J 14(10): 2283-2291.

50. Jackson LN, Chen LA, Larson SD, Silva SR, Rychahou PG, et al. (2009) Development and characterization of a novel in vivo model of carcinoid syndrome. Clin Cancer Res 15(8): 2747-2755.

51. Strosberg J, El-Haddad G, Wolin E, Hendifar A, Yao J, et al. (2017) Phase 3 Trial of 177Lu-Dotatate for Midgut Neuroendocrine Tumors. N Engl J Med 376(2): 125-135.

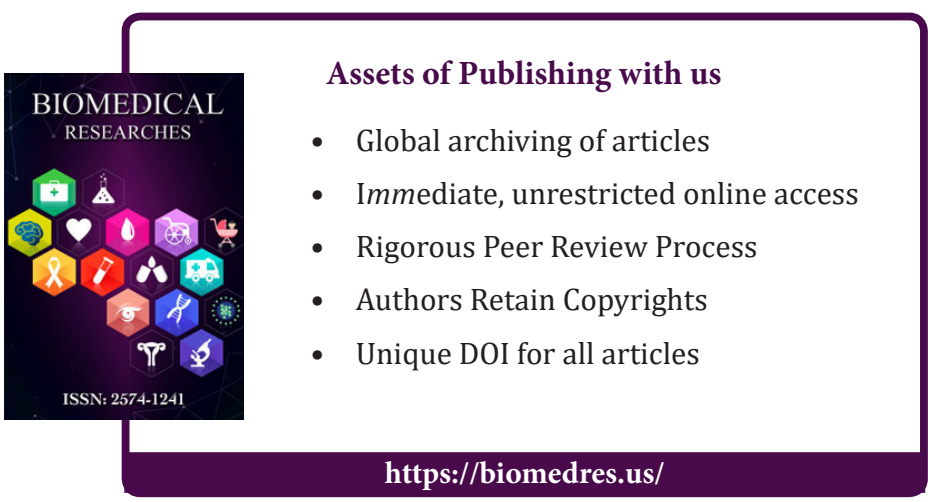

